\title{
Phylo- and Ontogenetic Fears and the Expectation of Danger: Differences Between Spider- and Flight-Phobic Subjects in Cognitive and Physiological Responses to Disorder-Specific Stimuli
}

\author{
Andreas Mühlberger \\ University of Würzburg
}

\author{
Georg Wiedemann \\ University of Frankfurt
}

\author{
Martin J. Herrmann and Paul Pauli \\ University of Würzburg
}

\begin{abstract}
To compare specific phobias with an assumed phylogenetic or ontogenetic origin in responses to fear-relevant (FR) stimuli, 17 spider- and 17 flight-phobic participants were exposed to pictures of spiders, flight accidents, or mushrooms randomly followed by either a startling noise or nothing else. While both groups showed a disorder-specific expectancy bias, only spider-phobic participants exhibited a disorder-specific covariation bias. Spider-phobic participants also showed enhanced skin conductance responses (SCRs), event-related brain potentials (ERPs), and startle responses triggered by disorderspecific FR pictures while flight-phobic participants showed only disorder-specific enhanced SCRs. In sum, our direct comparison between ontogenetic and phylogenetic phobias revealed that the former is characterized by biased and enhanced responses triggered by disorder-specific FR stimuli presumably based on a biological preparedness.
\end{abstract}

Keywords: affective picture processing, event-related potentials, ERP, startle reflex, SCR

Seligman (1971) suggested that humans as well as animals may be biologically prepared to associate negative emotional states more readily with stimuli that represented a real or potential threat to the species' evolutionary ancestors than with stimuli that did not present a threat. Consistent with this assumption, superior conditioning and especially resistance to extinction were demonstrated for fear-relevant (FR) or phylogenetic-prepared stimuli (see Seligmann, 1971) paired with aversive outcomes (e.g., unpleasant noise following the stimuli) relative to fear-irrelevant (FI) or unprepared stimuli paired with aversive outcomes (for a review, see Öhman \& Mineka, 2001). Since perception of contingency often seems to be necessary for conditioning to occur, Tomarken, Mineka, and Cook (1989) suggested that these effects may reflect a more general covariation bias for FR stimuli and aversive outcomes. Based on an illusory correlation paradigm, Tomarken et al. presented to their

Andreas Mühlberger and Paul Pauli, Department of Psychology, Biological Psychology, Clinical Psychology, and Psychotherapy, University of Würzburg; Georg Wiedemann, University Hospital of Psychiatry and Psychotherapy, University of Frankfurt; and Martin J. Herrmann, University Hospital of Psychiatry and Psychotherapy, University of Würzburg.

This work was supported by the Deutsche Akademie für Flugmedizin (German Academy for Flight Medicine) with a grant to Drs. Pauli and Wiedemann and by the German Research Foundation (DFG) with a stipend to Dr. Mühlberger.

Correspondence concerning this article should be addressed to Andreas Mühlberger, Ph.D, Department of Psychology, Biological Psychology, Clinical Psychology, and Psychotherapy, University of Würzburg, Marcusstr, 9-11, D-97070 Würzburg, Germany. E-mail: muehlberger@ psychologie.uni-wuerzburg.de participants both FR (pictures of snakes or spiders) and FI stimuli (pictures of flowers and mushrooms) which were equally likely to be followed by either mild electric shocks, tones, or nothing else. A covariation bias was demonstrated since high-fear (spider or snake) but not low-fear participants significantly overestimated the covariation between FR slides and aversive outcomes relative to other slide and outcome combinations. Replication studies have demonstrated a covariation bias for participants with high fear of snakes or spiders (e.g., Kennedy, Rapee, \& Mazurski, 1997; Tomarken, Sutton, \& Mineka, 1995) or untreated spider-phobic participants (De Jong, Merckelbach, Arntz, \& Nijman, 1992).

To support Seligman's (1971) preparedness hypothesis, however, it is necessary to demonstrate differential covariation bias effects for phylogenetic versus ontogenetic FR stimuli. Based on the design of Hugdahl and Kärker (1981), Tomarken et al. examined covariation biases of participants with high and low fear of snakes for phylogenetic (slides of snakes) or ontogenetic (slides of damaged electrical outlets) FR stimuli. In line with the preparedness hypothesis, high snake fear participants showed a covariation bias for snakes and shock combinations but not for electrical outlets and shock combinations. Comparable results were reported by De Jong, Merckelbach, and Arntz (1995), who examined spider-phobic participants and used spiders and weapons as phylogenetic and ontogenetic FR stimuli, respectively. Kennedy et al. (1997) used participants with prior fear of the phylogenetic FR stimuli (snakes or spiders) and of the ontogenetic FR stimuli (damaged electrical outlets) in order to examine whether high fear of ontogenetic FR stimuli would be reflected in a covariation bias. Only high-fear participants demonstrated a covariation bias that was specific to phylogenetic FR slide and shock combinations. 
However, since participants feared both phylogenetic and ontogenetic stimuli, a covariation bias for ontogenetic stimuli might have been overshadowed by a strong effect for phylogenetic stimuli. In line with this argument, the two studies which found a covariation bias for ontogenetic FR stimuli presented these stimuli in comparison to two categories of FI stimuli, and phylogenetic FR stimuli were not presented at all. Davey and Dixon (1996) compared gun and electricity outlet slides with flower and landscape slides; Pauli, Wiedemann, \& Montoya (1998) examined crashed airplane slides in comparison to positive airplane and erotic slides. In sum, all studies have confounds that make the results ambiguous. Therefore, future studies should compare participants who fear either ontogenetic or phylogenetic FR stimuli and use phylogenetic and ontogenetic FR stimuli. Then, the origin of the fear (ontogenetic vs. phylogenetic) and the actual fear stimuli are manipulated separately, and effects could be interpreted unambiguously.

The covariation bias observed after an illusory correlation experiment (termed a posteriori covariation bias) presumably derives from the preexperimental expectancy that shocks might follow FR stimuli (Davey, 1992; Öhman \& Mineka, 2001; Pauli, Montoya, \& Martz, 1996). Several studies which assessed covariation bias before the experiment (termed a priori covariation bias or expectancy bias) or during the first experimental trials (termed on-line covariation bias) found evidence of elevated expectancies that shocks would follow both phylo- and ontogenetic FR stimuli in high- and low-fear participants (Amin \& Lovibond, 1997; De Jong \& Merckelbach, 1993; Kennedy et al., 1997; Pauli et al., 1996). An a posteriori covariation bias assessed after the experiment may be the consequence of an inefficient or slow correction process in high-fear participants regarding the covariation between phylogenetic FR stimuli and aversive outcomes (Amrhein, Pauli, Dengler, \& Wiedemann, 2005). Similarly, the experience of a relatively high contingency between FR stimuli and negative outcomes can induce an a posteriori covariation bias even in low-fear participants (Pauli et al., 1996; Tomarken et al., 1989), but not the experience of a high contingency between FI stimuli and aversive outcomes (Pauli, Montoya, \& Martz, 2001).

Conditioning as well as covariation bias studies demonstrated FR-selective associations, the former chiefly on the basis of physiological responses (mostly autonomic conditioned responses) as dependent variables, the latter mainly on the basis of judgments of covariation (see Öhman \& Mineka, 2001). The use of psychophysiological variables in covariation bias experiments may help to circumvent the problem that judgments of covariation are highly susceptible to experimental demand, and their use may provide additional information about the processing of FR and FI stimuli, the triggered expectancy processes, and the reactions to the delivered consequences.

Few previous covariation bias studies examined skin conductance responses (SCR) triggered by FR and FI stimuli, by the outcomes, or both (De Jong et al., 1995). SCRs mainly paralleled covariation bias findings; high-fear participants showed enhanced SCRs triggered by FR stimuli compared to FI stimuli, and enhanced SCRs triggered by aversive outcomes following FR stimuli. While the former can be interpreted as a heightened physiological arousal triggered by FR stimuli, the latter presumably reflects a match between participants' responses to FR stimuli and aversive outcomes (De Jong et al., 1995), and this match may promote a covariation bias (Tomarken et al., 1995). Other physi- ological measures which were successfully used to characterize emotional responses associated with the processing of affective stimuli are the acoustic startle response (ASR) (e.g., Pauli, Diedrich, \& Müller, 2002) and event-related brain potentials (ERPs) (e.g., Amrhein, Pauli, Mühlberger, \& Wiedemann, 2004; Pauli et al., 1997). Both measures may offer additional information about the mechanisms underlying covariation bias.

A large body of literature demonstrated that the ASR is modulated by foreground pictures; negatively valenced pictures enhance and positively valenced pictures diminish the ASR (Lang, 1995). Moreover, startle responses elicited during presentation of negative FR stimuli are higher in phobic and panic patients than in healthy control participants (Cook, Melamed, Cuthbert, McNeil, \& Lang, 1988; Grillon, Ameli, Goddard, Woods, \& Davis, 1994; Hamm, Cuthbert, Globisch, \& Vaitl, 1997). Furthermore, the expectation of an aversive outcome may affect the response to the startle stimuli, and covariation bias and startle modulation can be observed in the same experiment (Pauli et al., 2002; vanOyen Witvliet \& Vrana, 2000).

Additionally, several studies demonstrated that meaning and affective valence of stimuli affect cortical processes as reflected in ERPs. In these studies, the electrocortical changes following specific events as picture presentations are assessed by averaging the electrocortical responses of an individual across one stimulus category (e.g., negative pictures). Based on these averages, specific ERP components (e.g., P300 amplitude) that reflect the activity of distinct cortical sources and presumably specific cognitive processes are extracted and used to analyze differences between stimulus categories or groups of participants statistically.

In general, affective stimuli have been found to be associated with an enhanced P300 component (Keil et al., 2002; Kostandov \& Arzumanov, 1977; Naumann, Bartussek, Diedrich, \& Laufer, 1992), positive slow wave (PSW) amplitudes (e.g., Amrhein et al., 2004; Cuthbert, Schupp, Bradley, Birbaumer, \& Lang, 2000; Keil et al., 2002; Naumann et al., 1992; Pauli et al., 2001; Schupp et al., 2000), and longer-lasting positivity (up to 6 s; Amrhein et al., 2004; Cuthbert et al., 2000). Furthermore, higher amplitudes for the N2 and P2 and partially the P1 component triggered by startle probes during viewing of affective pictures were reported (Schupp, Cuthbert, Bradley, Birbaumer, \& Lang, 1997), as well as an N1 effect depending on picture content (Keil et al., 2002). Finally, Gardner, Cacioppo, Crites, and Berntson (1994) as well as Pauli et al. (1997) presented evidence that disorder-relevant stimuli elicit larger PSWs in phobic or panic patients, respectively, than in healthy control participants. In sum, there is evidence for a facilitated early processing of emotional stimuli reflected in earlier components of the ERP (e.g., N1, and P2) and for a deeper conscious evaluation of emotional stimuli reflected in later components (e.g., PSW).

The present study was designed to examine covariation bias and physiological reactions of spider-phobic and aviophobic participants triggered by phylogenetic FR stimuli (spiders), ontogenetic FR stimuli (airplane crashes), and FI stimuli (mushrooms). We were especially interested in the interaction between the type of FR stimulus (phylo- vs. ontogenetic) and individual fear (phylo- vs. ontogenetic origin). Our main hypothesis was that aviophobic and spider-phobic participants would exhibit an expectancy bias at the outset of the experiment, but that only spider-phobic participants would show a covariation bias after the experiment. We also 
expected that the direct comparisons between groups would reveal stronger and longer-lasting physiological reactions of spiderphobic participants compared to aviophobic participants triggered by their FR stimuli.

\section{Method}

\section{Participants}

Participants were paid volunteers recruited through local newspaper articles informing about a research project on spider and flight phobia. At the time of recruitment, each respondent was screened for Diagnostic and Statistical Manual of Mental Disorders' (4th ed.; DSM-IV; American Psychiatric Association, 1994) criteria of specific phobia (either spider or flight phobia). Diagnosis was inferred from eight questions that were constructed according to the $D S M-I V$ criteria and afterwards confirmed during an interview before the experiment. Additionally, participants completed the Fear of Flying Scale (FFS; Haug et al., 1987) and the Spider Questionnaire (SPQ; Klorman, Weerts, Hastings, Melamed, \& Lang, 1974). Exclusion criteria were fulfilling diagnostic criteria of both spider and flight phobia or showing enhanced questionnaire responses in the FFS and the SPQ (both scores in the 1st quartile; for reference data, see Johnsen \& Hugdahl, 1990), actually taking drugs, and actually taking part in psychotherapy. Seventeen flight-phobic participants (3 men, 14 women; age: $M=44.2$ years, $S D=9.6$ years $)$ and 17 spider-phobic participants $(1$ man, 16 women; age: $M=27.4$ years, $S D=9.3$ ) completed the study. Two spider-phobic participants did not meet all diagnostic criteria of spider phobia, because they did not consider their anxiety as irrational or too excessive. However, both scored within the upper 5\% on the SPQ and therefore were included. All participants except for 2 spider-phobic participants were right-handed. There were no differences between groups in state or trait anxiety (Spielberger, Gorsuch, \& Lushene, 1970; German version by Laux, Glanzmann, Schaffner, \& Spielberger, 1981) or any index of the Symptom Checklist 90-Revised (SCL-90-R) (Franke, 1995) (all $p>.20$ ).

Equipment failure led to missing data for 3 participants in the SCL and EMG measures in Block 2 (see below). Furthermore, 2 participants of the flight phobia group had to be excluded from the EEG analyses because they reported having had brain surgery more than ten years earlier. Each participant received $4 €$ per hour for participating in the study.

\section{Subjective Measures}

A priori expectancies were assessed before the first experimental block based on the instructions of McNally and Heatherton (1993). On visual analogue scales (VAS), participants rated their expectancy of how frequently a startle tone would follow a specific picture category (airplane crash, spider, or mushroom) in the following experiment.

Covariation estimates were assessed after each experimental block. Participants were asked to judge on a VAS the frequency and unpleasantness of startle stimuli following each picture category. In addition, participants rated how frequently pictures of each category were presented (picture-frequency estimates).

\section{Materials and Design}

Pictures. Pictures relevant to fear of flying (three of airplane crashes) and to fear of spiders (three of spiders) as well as FI pictures (three of mushrooms) were used. Airplane crashes and spiders were selected on the basis of a pilot study. Twelve students ( 7 females and 5 males; age: $M=$ $22.3 \pm 3.4)$ rated nine pictures per category for arousal and valence (Self-Assessment Manikin ratings; Lang, 1980) and for anxiety and familiarity (scales from 0 to 10 ). The selected three airplane crashes and three spider pictures did not differ in mean valence (spiders $=6.1$; airplane crashes $=6.6$ ), mean arousal ( spiders $=4.1$; airplane crashes $=4.4)$, mean anxiety (spiders $=4.2$; airplane crashes $=3.9$ ), or mean familiarity ratings ( spiders $=3.3$; airplane crashes $=3.9$ ).

In the main experiment, each picture presentation trial started with a fixation cross (random duration between 1 and $3 \mathrm{~s}$ ), followed by the presentation of one picture (for $6 \mathrm{~s}$ ). Outcomes (startle stimuli or nothing else) were presented with the picture offset. The intertrial interval (ITI) varied randomly between 10 and $15 \mathrm{~s}$ in 1 -s increments. The startle stimulus was presented after $50 \%$ of the picture presentations of each category. Our paradigm differs slightly from traditional fear-potentiated startle paradigms since we did not include startle probes randomly during the ITI.

The serial order of picture presentations and the order of outcomes, as well as duration of ITI and fixation cross, were counterbalanced and pseudorandomized in three predefined orders (A, B, or C). Within each order, pictures were arranged such that not more than two trials with pictures of the same category and not more than two trials with aversive outcomes (startle presentation) followed each other. For each participant, one of six presentation orders was selected (ABC, ACB, BAC, BCA, CAB, or CBA).

Outcomes. The aversive outcome was a $50 \mathrm{~ms}$ burst of white noise $(103 \mathrm{~dB})$ with instantaneous rise time. Startle stimuli were presented binaurally over headphones.

\section{Procedure}

After obtaining informed consent, which included the presentation of two startle probes, subjects were seated in a comfortable chair in a sound-attenuated room next to the experimenter's room. Physiological sensors were attached and baseline measures were registered. After that, participants were instructed that in the first part of the experiment, pictures of different emotional content would be presented on a screen. They were asked to look at each picture during the entire presentation time and to ignore the noise presented via headphones. All presentations (pictures and instructions) were projected with an image size of 110 by $80 \mathrm{~cm}$ onto a white screen at a distance of $2 \mathrm{~m}$ in front of the participant's head.

After these preparations, state anxiety (Spielberger et al., 1970) and preexperimental expectancy estimates were assessed. Then, three startle probes were delivered in order to habituate the participants. The main experiment was divided into two blocks of picture presentations to allow an assessment of changes in cognitive and physiological parameters due to the corrective impact of the actual consequences given during the experiment. In each of the two experimental blocks, 36 pictures were presented, 12 of each category (each of the three pictures of one category was presented four times). After each block, the covariation estimates, the picture frequency estimates, and the ratings of the startle probes' valence depending on the slide category (spiders, airplane crashes, or mushrooms) were registered. The time interval between the two blocks was approximately 3 min.; participants completed questionnaires and were able to relax.

\section{Physiological Recording and Data Reduction}

EEG recording. EEG was recorded continuously with a sampling rate of $200 \mathrm{~Hz}$ with $\mathrm{Ag} / \mathrm{AgCl}$ - electrodes from 13 sides according to the $10-20$ system (frontal: FP1, FP2, F3, FZ, F4; central: C3, CZ, C4; parietal: P3, $\mathrm{PZ}, \mathrm{P} 4$; and occipital: $\mathrm{O} 1, \mathrm{O} 2$ ) and the right mastoid (A2), all referenced to the left mastoid (A1). An electrode at FCZ was used as ground. Electrooculographic artifacts were monitored with electrodes at supra- and infraorbital sites of the right eye for vertical eye movements and at outer canthi of both eyes for horizontal eye movements (both bipolar). EEG data were recorded with a Synamps amplifier set at $10 \mathrm{~K} \Omega$ gain in DC mode using the software Scan 4.1 (Neuroscan, Inc., Hamburg, Germany) with a low pass filter of $40 \mathrm{~Hz}$.

Signals were analyzed offline with the BrainVision Analyzer Software of BrainProducts, Inc. (Munich, Germany). First, data were re-referenced 
to linked mastoids, filtered with a low cutoff of $0.01 \mathrm{~Hz}(12 \mathrm{~dB} / \mathrm{octave})$ and a high cutoff of $10 \mathrm{~Hz}$ (12 dB/octave), and segmented from $200 \mathrm{~ms}$ before picture onset to $6,000 \mathrm{~ms}$ after picture onset. Then, ocular artifacts were corrected according to the algorithm of Gratton and Coles (see Gratton, 1998) with raw average subtraction for both horizontal and vertical electrooculographic artifacts. Baseline correction was performed using the 200-ms prestimulus. Only nine electrodes (P3, Pz, P4, C3, Cz, C4, P3, Pz, and $\mathrm{P} 4)$ were further analyzed. Artifact rejection used a voltage change cutoff of $50 \mu \mathrm{V}$, a maximum allowed difference of $130 \mu \mathrm{V}$ within a trial, and a maximum allowed amplitude of $\pm 100 \mu \mathrm{V}$. Trials were averaged separately for picture categories and participants. N1 was searched in a time window between 70 and $130 \mathrm{~ms}, \mathrm{P} 2$ between 90 and $160 \mathrm{~ms}, \mathrm{~N} 2$ between 130 and $220 \mathrm{~ms}$, and P300 between 280 and $450 \mathrm{~ms}$ after picture onset as local minima and maxima. PSW was calculated as mean from 600 to $800 \mathrm{~ms}$ after picture onset. Early contingent negative variation (CNV) was defined as mean from 1,000 to $3,000 \mathrm{~ms}$, and late $\mathrm{CNV}$ as mean from 3,000 to $6,000 \mathrm{~ms}$ after picture onset. To improve the signal-to-noise ratio, the trials of Block 1 and Block 2 were analyzed together, resulting in potentially 24 trials per picture category and participant. Only participants with at least 10 artifact-free epochs per category were statistically analyzed. Following these criteria, 3 spider-phobic participants and 1 flightphobic participant had to be excluded. One additional spider-phobic participant had to be excluded from the late-CNV analysis because of less than 10 artifact-free epochs.

EMG and skin conductance. EMG and skin conductance were registered continuously with a Vitaport-I system (Becker Meditec, Inc., Karlsruhe, Germany). The eye-blink component of the startle reflex was measured by recording electromyographic (EMG) activity from the M. orbicularis oculi muscle beneath the left eye with $\mathrm{Ag} / \mathrm{AgCl}$ miniature electrodes attached with a constant interelectrode distance $(2.5 \mathrm{~cm})$ across subjects. The raw signal was sampled at $400 \mathrm{~Hz}$, rectified online, and integrated with a time constant of $15 \mathrm{~ms}$. Responses to the startle probes were scored manually and defined as an EMG peak in a time window from 20 to $250 \mathrm{~ms}$ after probe presentation (see Codispoti, Bradley, \& Lang, 2001). Trials with excessive baseline shifts or movement artifacts were excluded; trials with no detectable reaction were scored as zero. Differences between absolute startle amplitude and baseline EMG (0 to $20 \mathrm{~ms}$ after the startle presentation) were calculated (see Grillon \& Ameli, 1998). Startle response magnitudes were then standardized within subjects to correct for the disproportionate influence of outliers. Therefore, raw data were first $\mathrm{z}$ - and then T-transformed (see Globisch, Hamm, Esteves, \& Öhman, 1999; Hamm et al., 1997). Two spider-phobic participants and 1 flight-phobic participant were excluded because of less than four artifactfree trials per category.
Skin conductance was recorded from two electrodes placed on the medial phalanges of the second and third finger of the nondominant hand. The Vitaport-I system delivered constantly $0.5 \mathrm{~V}$ and measured skin conductance with a sampling rate of $400 \mathrm{~Hz}$. SCRs elicited by the pictures were scored manually and defined as the largest increase in conductance in a time window from 1.5 to $6.0 \mathrm{~s}$ after picture onset. As for startle reflex, trials with artifacts were excluded from analysis, whereas trials with no detectable response were scored as zero. Differences between SCR amplitude and baseline level (root point before reaction onset) were calculated. Subjects with less than eight artifact-free trials per category were excluded from this analysis-1 flight-phobic participant in Block 1, and 2 spiderphobic participants and 1 flight-phobic participant in Block 2.

\section{Statistical Data Analysis}

Expectancy estimates, covariation estimates, SCR, and startle responses were analyzed with mixed ANOVAs with the between subject factor Phobia (flight vs. spider phobia) and the within subject factor Picture Category (airplane, spider, and mushroom pictures). ANOVAs on ERP peaks and CNV epochs had the additional within-subject factors Laterality (left, middle, and right electrodes) and Frontality (frontal, central, and parietal electrodes). Age and gender differences between groups were controlled by including these variables as covariates. Significant category by group interactions were further analyzed with ANOVAs within groups and contrasts between FR and FI pictures. Significant ERP effects involving category by group by electrode interactions were followed by ANOVAs for individual electrodes.

Data analyses were performed with SPSS Version 11.0. If appropriate, Greenhouse-Geisser corrections of degrees of freedom were applied.

\section{Results}

Table 1 depicts the expectancy, covariation estimates, and picture frequency ratings as well as the skin conductance and startle responses of spider- and flight-phobic participants differentiated for picture categories and experimental blocks.

\section{Expectancy Estimates}

The overall analysis revealed only significant category, $F(2$, $64)=21.6, p<.001, \eta_{\mathrm{p}}^{2}=.40$, and group by category, $F(2,64)=$ $11.5, p<.001, \eta_{\mathrm{p}}^{2}=.27$, effects. ANOVAs within groups returned significant category effects for flight-phobic participants,

Table 1

Results Differentiated for Picture Categories and Experimental Blocks

\begin{tabular}{|c|c|c|c|c|c|c|}
\hline \multirow[b]{2}{*}{ Measure } & \multicolumn{3}{|c|}{ Flight-phobic participants } & \multicolumn{3}{|c|}{ Spider-phobic participants } \\
\hline & Spiders & Airplanes & Mushrooms & Spiders & Airplanes & Mushrooms \\
\hline Expectancy esti & $.5(18.8)$ & $68.0(16.5)$ & $25.2(24.5)$ & $56.0(24.2)$ & $40.0(23.1)$ & $18.7(2$ \\
\hline Covariation estima & $7.9(13.6)$ & $50.7(17.6)$ & $45.2(15.1)$ & $57.9(19.2)$ & $47.9(17.6)$ & $34.1(19.2)$ \\
\hline Covariation estimate 2 & $47.4(17.5)$ & $48.4(14.5)$ & $46.0(20.1)$ & $46.8(18.4)$ & 39.4 (13.6) & $34.2(20.1)$ \\
\hline Picture frequency estimate 1 & $34.2(10.4)$ & $40.1(17.7)$ & $33.8(12.1)$ & $43.1(19.1)$ & $44.1(13.5)$ & $41.1(15.5)$ \\
\hline Picture frequency estimate 2 & $38.7(14.3)$ & $36.7(10.0)$ & $38.6(17.6)$ & $50.5(19.4)$ & $42.1(15.5)$ & $40.3(18.1)$ \\
\hline Startle valence 1 (range $0-10$ ) & $4.6(2.4)$ & $5.8(2.3)$ & $4.7(2.6)$ & $7.9(2.6)$ & $4.4(2.8)$ & $3.8(3.0)$ \\
\hline Startle valence 2 (range $0-10$ ) & $3.4(2.0)$ & 4.1( & $3.6(1.8)$ & $7.8(1.9)$ & $4.2(2.7)$ & $3.6(2.7)$ \\
\hline SCR, Block 1 (T scores) & $49.8(1.8)$ & $51.5(1.57)$ & $48.7(1.7)$ & $55.5(3.6)$ & $47.0(2.4)$ & $47.6(2.7)$ \\
\hline SCR, Block 2 (T scores) ${ }^{\mathrm{a}}$ & $49.8(2.7)$ & $50.4(3.0)$ & $49.8(2.7)$ & $52.5(3.5)$ & $48.6(3.1)$ & $48.8(2.7)$ \\
\hline Startle, Block 1 (T scores) $^{\mathrm{b}}$ & $50.1(3.5)$ & $51.4(3.6)$ & $48.5(2.9)$ & $52.6(4.3)$ & $49.0(3.0)$ & $48.2(3.9)$ \\
\hline Startle, Block 2 (T scores) $^{\mathrm{a}}$ & $51.9(3.4)$ & $50.1(2.9)$ & $47.9(2.4)$ & $52.1(4.6)$ & $49.2(2.5)$ & $48.8(3.9)$ \\
\hline
\end{tabular}

Note. Means and (standard deviations) are presented.

${ }^{\mathrm{a}} N=16 / 15$. ${ }^{\mathrm{b}} N=16 / 17$. 
$F(2,32)=21.2, p<.001, \eta_{\mathrm{p}}^{2}=.57$, and spider-phobic participants, $F(2,32)=12.6, p<.001, \eta_{\mathrm{p}}^{2}=.44$. Contrasts within the flight-phobic group revealed higher expectancy estimates for airplane pictures compared to spider pictures, $F(1,16)=26.6, p<$ $.001, \eta_{\mathrm{p}}^{2}=.62$, or mushroom pictures, $F(1,16)=31.7, p<.001$, $\eta_{\mathrm{p}}^{2}=.67$. For spider-phobic participants, the expectancy estimates were higher for spider than airplane pictures, $F(1,16)=5.6, p=$ $.031, \eta_{\mathrm{p}}^{2}=.26$, or mushroom pictures, $F(1,16)=18.0, p=.001$, $\eta_{\mathrm{p}}^{2}=.53$.

\section{Covariation Estimate}

Block 1. The overall analysis returned only significant category, $F(2,64)=9.1, p<.001, \eta_{\mathrm{p}}^{2}=.22$, and group by category, $F(2,64)=5.4, p=.008, \eta_{\mathrm{p}}^{2}=.14$, effects. ANOVAs within groups revealed a significant category effect for spider-phobic participants, $F(2,32)=9.4, p=.001, \eta_{\mathrm{p}}^{2}=.37$, but not for flight-phobic participants. Within spider-phobic participants, contrasts revealed significantly higher estimates for spider compared to mushroom pictures, $F(1,16)=13.9, p=.002, \eta_{\mathrm{p}}^{2}=.47$, and marginally higher estimates for spider compared to airplane pictures, $F(1,16)=3.8, p=.069, \eta_{\mathrm{p}}^{2}=.19$.

Block 2. The overall analysis revealed no significant effects, specifically no category, $F(2,64)=2.7, p=.073, \eta_{\mathrm{p}}^{2}=.08$, or group by category, $F(2,64)=1.9, p=.157, \eta_{\mathrm{p}}^{2}=.06$, effects.

\section{Picture Frequency Estimates}

Block 1. The overall analysis for Block 1 revealed no significant effects, specifically no category, $F(2,64)=1.2, p=.296$, $\eta_{\mathrm{p}}^{2}=.04$, or group by category, $F(2,64)=0.3, p=.710, \eta_{\mathrm{p}}^{2}=$ .01 , effects.

Block 2. The overall analysis for Block 2 also revealed no significant effects, specifically no category, $F(2,64)=1.9, p=$ $.160, \eta_{\mathrm{p}}^{2}=.06$, or group by category, $F(2,64)=1.4, p=.26, \eta_{\mathrm{p}}^{2}=$ .04 , effects.

\section{Startle Valence}

Block 1. The overall analysis for Block 1 returned only significant category, $F(2,64)=7.0, p=.004, \eta_{\mathrm{p}}^{2}=.18$, and group by category, $F(2,64)=11.4, p<.001, \eta_{\mathrm{p}}^{2}=.26$, effects. ANOVAs within groups revealed a significant category effect for spider-phobic participants, $F(2,32)=11.1, p=.003, \eta_{\mathrm{p}}^{2}=.41$, but not for flight-phobic participants, $F(2,32)=3.2, p=.076$, $\eta_{\mathrm{p}}^{2}=.17$. For spider-phobic participants, the startle valence was more negative after spider than airplane pictures, $F(1,16)=11.1$, $p=.004, \eta_{\mathrm{p}}^{2}=.41$, or mushroom pictures, $F(1,16)=12.1, p=$ $.003, \eta_{\mathrm{p}}^{2}=.43$.

Block 2. The overall analysis for Block 2 revealed significant category, $F(2,64)=12.0, p<.001, \eta_{\mathrm{p}}^{2}=.27$; group by category, $F(2,64)=16.6, p<.001, \eta_{\mathrm{p}}^{2}=.34$; and group, $F(1,32)=7.2$, $p=.011, \eta_{\mathrm{p}}^{2}=.18$, effects. ANOVAs within groups revealed a significant category effect for spider-phobic participants, $F(2$, $32)=16.2, p<.001, \eta_{\mathrm{p}}^{2}=.50$, but not for flight-phobic participants, $F(2,32)=2.4, p=.130, \eta_{\mathrm{p}}^{2}=.13$. For spider-phobic participants, the startle valence was more negative after spider than airplane pictures, $F(1,16)=15.0, p=.001, \eta_{\mathrm{p}}^{2}=.48$, or mushroom pictures, $F(1,16)=21.0, p<.001, \eta_{\mathrm{p}}^{2}=.57$.

\section{Skin Conductance Response}

Block 1. The overall analysis revealed only significant category, $F(2,64)=21.6, p<.001, \eta_{\mathrm{p}}^{2}=.40$, and group by category, $F(2,64)=25.9, p<.001, \eta_{\mathrm{p}}^{2}=.45$, effects. Within the flightphobic group, the significant category effect, $F(2,32)=7.2, p=$ $.003, \eta_{\mathrm{p}}^{2}=.31$, can be traced back to higher SCRs triggered by airplane compared to spider pictures, $F(1,16)=4.7, p=.046$, $\eta_{\mathrm{p}}^{2}=.23$, or mushroom pictures, $F(1,16)=15.6, p=.001, \eta_{\mathrm{p}}^{2}=$ .49 . Within the spider-phobic group, the significant category effect, $F(2,32)=29.6, p<.001, \eta_{\mathrm{p}}^{2}=.65$, was due to higher SCRs following spider compared to airplane pictures, $F(1,16)=43.3$, $p<.001, \eta_{\mathrm{p}}^{2}=.73$, or mushroom pictures, $F(1,16)=31.4, p<$ $.001, \eta_{\mathrm{p}}^{2}=.66$.

Block 2. The overall analysis resulted only in a significant group by category, $F(2,58)=3.4, p=.044, \eta_{\mathrm{p}}^{2}=.10$, interaction; the main category effect was not significant, $F(2,58)=2.4, p=$ $.103, \eta_{\mathrm{p}}^{2}=.08$. Separate ANOVAs within groups revealed no significant category effects for flight-phobic participants. However, for spider-phobic participants, the significant category effect, $F(2,30)=5.2, p=.015, \eta_{\mathrm{p}}^{2}=.26$, was due to higher SCRs for spider compared to airplane pictures, $F(1,15)=6.4, p=.023$, $\eta_{\mathrm{p}}^{2}=.30$, or mushroom pictures, $F(1,15)=6.9, p=.019, \eta_{\mathrm{p}}^{2}=$ .32 .

\section{Acoustic Startle Response (ASR)}

Block 1. The overall ANOVA returned only a significant category effect, $F(2,62)=3.9, p=.027, \eta_{\mathrm{p}}^{2}=.11$, and a marginally significant group by category interaction, $F(2,62)=$ $2.7, p=.077, \eta_{\mathrm{p}}^{2}=.08$. Separate ANOVAs within groups revealed no significant category effect for flight-phobic participants. However, within the spider-phobic participants, the significant category effect, $F(2,30)=4.2, p=.031, \eta_{\mathrm{p}}^{2}=.22$, was due to higher startle responses following spider compared to airplane pictures, $F(1,15)=5.6, p=.032, \eta_{\mathrm{p}}^{2}=.27$, or mushroom pictures, $F(1,15)=5.4, p=.034, \eta_{\mathrm{p}}^{2}=.27$.

Block 2. The overall analysis revealed only a significant category effect, $F(2,58)=6.2, p=.007, \eta_{\mathrm{p}}^{2}=.18$, but no group by category interaction, $F(2,58)=0.3, p=.671, \eta_{\mathrm{p}}^{2}=.01$. Within the whole group of phobic participants, the contrasts between spider versus airplane pictures, $F(1,29)=4.6, p=.041, \eta_{\mathrm{p}}^{2}=.14$, and spider versus mushroom pictures, $F(1,29)=8.9, p=.006$, $\eta_{\mathrm{p}}^{2}=.24$, were significant.

\section{ERP Data}

N1. The overall ANOVA returned only significant frontality, $F(2,48)=17.6, p<.001, \eta_{\mathrm{p}}^{2}=.42$, and frontality by laterality effects, $F(2,96)=3.9, p=.014, \eta_{\mathrm{p}}^{2}=.14$.

N2. The overall ANOVA revealed only significant frontality, $F(2,48)=10.0, p=.001, \eta_{\mathrm{p}}^{2}=.29$; laterality, $F(2,48)=3.5, p=$ $.049, \eta_{\mathrm{p}}^{2}=.13$; category, $F(2,48)=3.8, p=.036, \eta_{\mathrm{p}}^{2}=.14$; and category by group, $F(2,48)=5.9, p=.007, \eta_{\mathrm{p}}^{2}=.20$, effects. Separate ANOVAs within groups revealed no significant category effects for spider-phobic participants. However, for flight-phobic participants, the significant category effect, $F(2,26)=7.6, p=$ $.003, \eta_{\mathrm{p}}^{2}=.37$, was due to an enhanced $\mathrm{N} 2$ for airplane in contrast 
to spider pictures, $F(1,13)=10.4, p=.007, \eta_{\mathrm{p}}^{2}=.44$, or mushroom pictures, $F(1,13)=9.5, p=.009, \eta_{\mathrm{p}}^{2}=.42$.

$P 2$. The overall ANOVA returned only a significant frontality effect, $F(2,48)=5.9, p=.021, \eta_{\mathrm{p}}^{2}=.20$ (see Figures 1 and 2 ).

$P 3$. The overall ANOVA revealed only significant frontality, $F(2,48)=15.5, p<.001, \eta_{\mathrm{p}}^{2}=.39$; category, $F(2,48)=3.4, p=$ $.047, \eta_{\mathrm{p}}^{2}=.12$; frontality by laterality, $F(2,48)=4.4, p=.005$, $\eta_{\mathrm{p}}^{2}=16$; and frontality by laterality by category by group effects, $F(8,192)=2.3, p=.041, \eta_{\mathrm{p}}^{2}=.09$. ANOVAs within spiderphobic participants revealed significant category effects for frontal and lateral central electrode sites, F3, Fz, F4, C3, C4; F(2, 26) > $6.4, p<.007, \eta_{\mathrm{p}}^{2}>$.33. For these electrodes, the P3 was significantly more pronounced for spider pictures in contrast to airplane or mushroom pictures, $F(1,13)>8.3, p<.013$. For flight-phobic participants, only a significant category effect for the electrode $\mathrm{Pz}$, $F(2,26)=4.1, p=.036, \eta_{\mathrm{p}}^{2}=.24$, due to a more pronounced $\mathrm{P} 3$ for airplane pictures in contrast to spider and mushroom pictures, $F(1,13)=4.9, p<.045$, was found.

$P S W$. The overall ANOVA revealed only significant frontal- ity, $F(2,42)=3.8, p=.042, \eta_{\mathrm{p}}^{2}=.15$, and group by category effects, $F(2,42)=5.2, p=.010, \eta_{\mathrm{p}}^{2}=.20$. Separate ANOVAs within groups revealed no significant category effects for flightphobic participants, $F(2,26)=2.8, p=.101, \eta_{\mathrm{p}}^{2}=.18$. However, for spider-phobic participants, the significant category effect, $F(2$, $26)=12.1, p<.001, \eta_{\mathrm{p}}^{2}=.48$, was due to a more positive PSW for spider pictures in contrast to airplane and mushroom pictures, $F(1,13)>13.5, p<.003, \eta_{\mathrm{p}}^{2}>.50$.

Early $C N V$. The overall ANOVA returned only a significant group by category effect, $F(2,42)=6.0, p=.011, \eta_{\mathrm{p}}^{2}=.22$. Separate ANOVAs within groups revealed a significant difference between categories in the spider group, $F(2,26)=8.9, p=.005$, $\eta_{\mathrm{p}}^{2}=.41$, and in the flight group, $F(2,26)=9.6, p=.003, \eta_{\mathrm{p}}^{2}=$ .42. For spider-phobic participants, the CNV was more positive for spider pictures in contrast to airplane and mushroom pictures, $F(1,13)>8.7, p<.011, \eta_{\mathrm{p}}^{2}>.40$. For flight-phobic participants, the CNV was more positive for airplane pictures in contrast to spider and mushroom pictures, $F(1,13)>5.1, p<$ $.042, \eta_{\mathrm{p}}^{2}>.28$.
F3

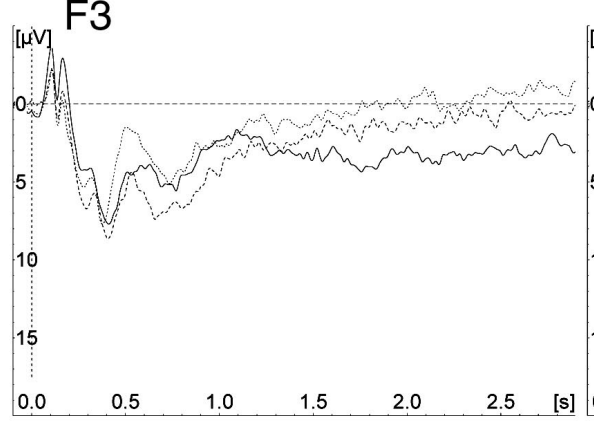

FZ

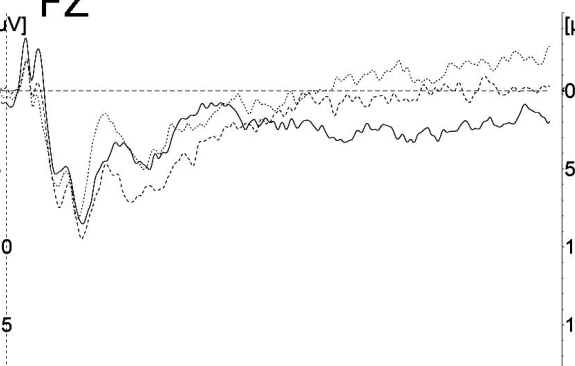

F4

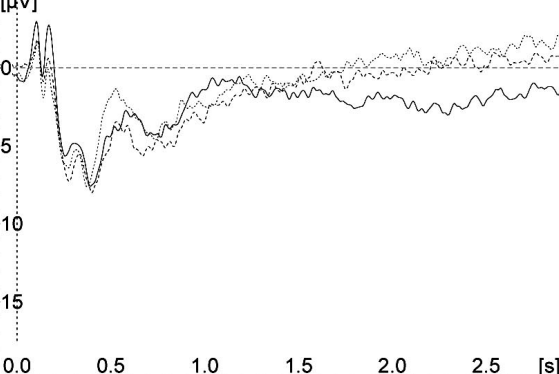

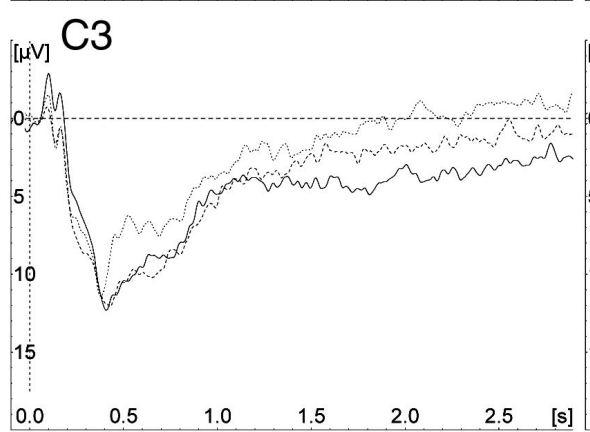

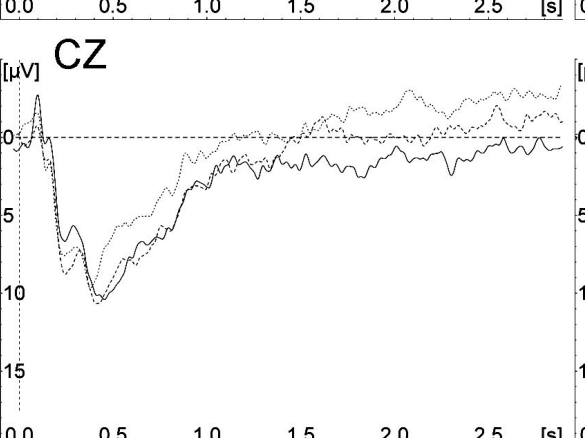

C4

$\mu \mathrm{v}$

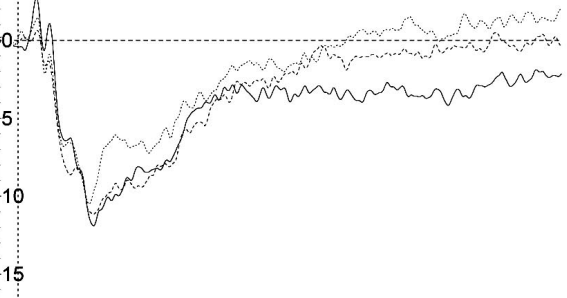

$\begin{array}{lllllll}0.0 & 0.5 & 1.0 & 1.5 & 2.0 & 2.5 & {[\mathrm{~s}]}\end{array}$


P4

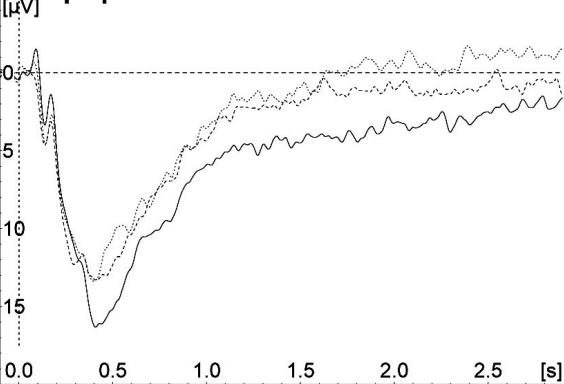

Figure 1. EKP responses (F3, FZ, F4, C3, CZ, C4, P3, PZ, and P4) for flight-phobics on spiders, airplanes, and mushrooms over a 3-s period after picture onset (solid lines: airplane crashes; dashed lines: spiders; teeny dashed lines: mushrooms). 
F3
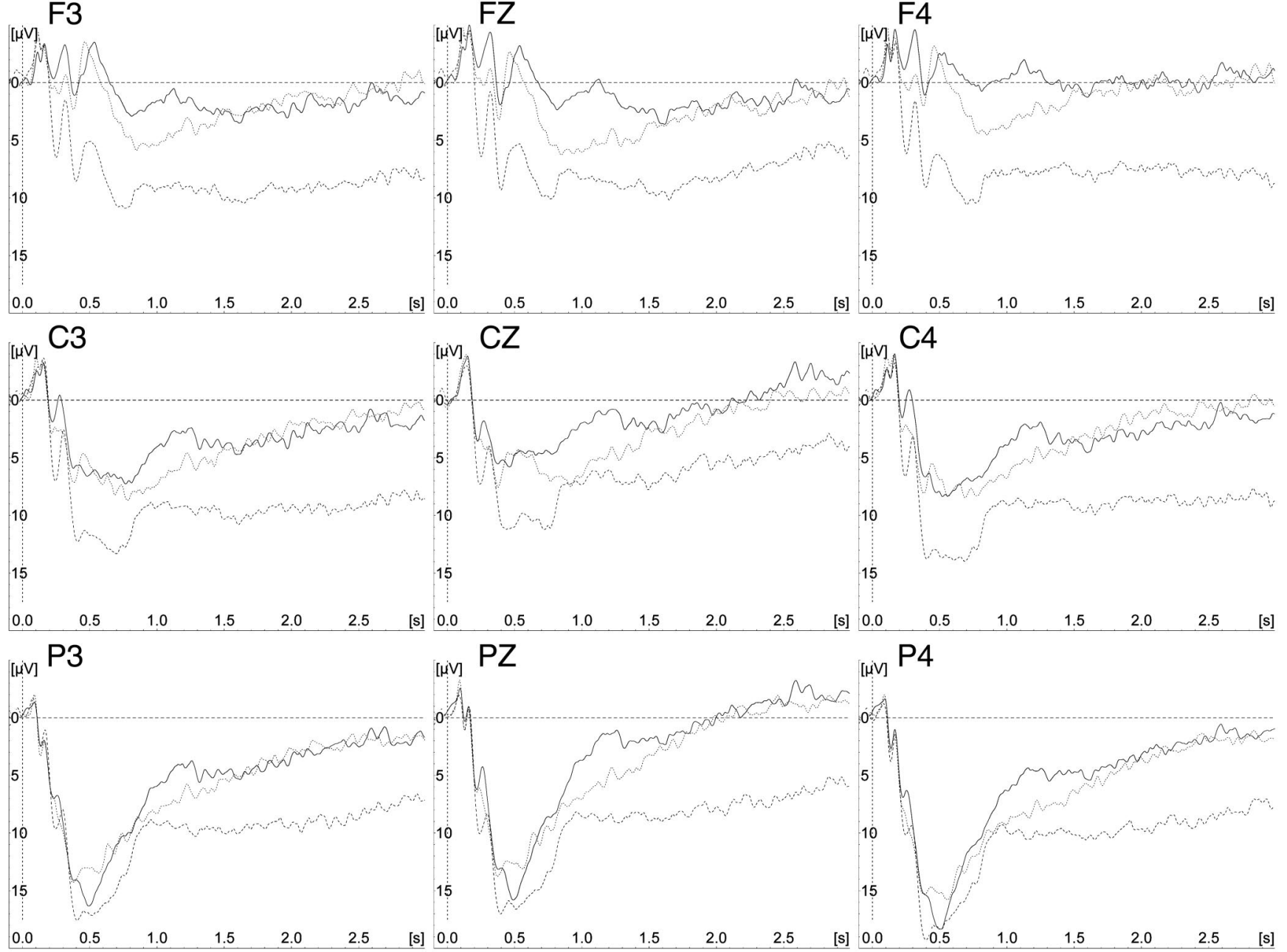

Figure 2. EKP responses (F3, FZ, F4, C3, CZ, C4, P3, PZ, and P4) for spider phobic participants on spiders, airplanes, and mushrooms over a 3 second period after picture onset (solid lines: airplane crashes; dashed lines: spiders; teeny dashed lines: mushrooms).

Late $C N V$. No overall ANOVA effect was detected, all $p>$ .10 , and the category by group effect was $F(2,26)=2.1, p=.131$, $\eta_{\mathrm{p}}^{2}=.10$.

\section{Discussion}

The present study examined differences between phylo- and ontogenetic fears regarding covariation bias and physiological responses to FR and FI pictures. Methodological flaws of previous covariation bias (CB) studies, as presented in the introduction, were overcome by comparing participants with either a specific ontogenetic fear or a specific phylogenetic fear. CBs were assessed before the experiment and after two illusory correlation blocks, and physiological reactions were assessed within these blocks. Before the experiment (a priori), both flight-phobic participants and spider-phobic participants revealed enhanced expectancies that their feared FR stimuli would be followed by aversive outcomes (startling white noise) relative to the alternative stimulus/ outcome combinations. After the first illusory correlation block, however, only participants with phylogenetic fear (spider-phobic participants) revealed a CB for their feared FR stimuli (spiders). In contrast, participants with ontogenetic fear (flight-phobic participants) showed no CB, neither for their feared FR stimuli (airplane crashes) nor for phylogenetic FR stimuli (spiders). Finally, after the second illusory correlation block, neither spider- nor flightphobic participants showed a CB.

The present study is, to our knowledge, the first that directly compared participants with phylo- or ontogenetic fears for their feared stimuli regarding $\mathrm{CB}$ and its change over three assessment points-before the experiment and after two illusory correlation blocks. Results confirm and extend previous findings of $\mathrm{CB}$ for phylo- and ontogenetic fears (e. g., Kennedy et al., 1997). Covariation estimates are presumably the result of preexperimental expectancies and situational information given during the experiment (Alloy \& Tabachnik, 1984). The present findings therefore might indicate that, on the one hand, phylo- and ontogenetic fears elicit comparable expectancies regarding aversive outcomes following 
the feared stimuli. On the other hand, phylo- and ontogenetic fears seem to differ in the way situational information affects covariation estimates. The given situational information of random contingencies led to unbiased covariation estimates in flight-phobic participants after one experimental block, while spider-phobic participants showed a CB after the same situational information. However, additional situational information of random contingencies during the second illusory correlation block led to unbiased covariation estimates also in spider-phobic participants. In other words, the correction of biased expectancies on the basis of situational information seems to be slower in participants with phylogenetic compared to ontogenetic fears. These results confirm the preparedness hypothesis (Öhman \& Mineka, 2001; Seligman, 1971) which assumes that phylogenetic FR stimuli are processed with a bias compared to ontogenetic FR stimuli. Noteworthy is that the present finding closely corresponds to findings of a resistance to extinction for phylogenetic FR stimuli associated with aversive outcomes revealed by conditioning studies examining the preparedness hypothesis (see Öhman \& Mineka, 2001). In both cases, situational information has a weaker effect on phylogenetic FR stimuli compared to ontogenetic FR stimuli.

The present results extend the findings of Kennedy et al. (1997) by showing that a $\mathrm{CB}$ is specific to phylogenetic FR stimuli; even participants with a specific ontogenetic fear show no CB for their feared ontogenetic FR stimuli.

The present study is also the first which simultaneously registered peripheral and central psychophysiological measures as well as startle response modulation during illusory correlation blocks. Startle responses elicited by the aversive outcomes following FR and FI pictures closely mirror the CB findings. On the one hand, spider-phobic participants but not flight-phobic participants exhibited enhanced startle responses triggered by the aversive outcomes following their feared FR stimuli compared to not-feared FR stimuli or neutral stimuli during the first illusory correlation block. On the other hand, spider- and flight-phobic participants showed no modulation of the startle response depending on the presented stimuli during the second illusory correlation block. Interestingly, the SCRs did not mirror this picture because flight- and spiderphobic participants showed enhanced SCRs triggered by their feared FR stimuli during the first experimental block, while only spider-phobic participants revealed enhanced SCRs triggered by their feared FR stimuli during the second experimental block. These physiological findings emphasize several important issues. First, the SCR findings confirm that both experimental groups responded emotionally to their relevant FR stimuli validating the selection of picture. Second, emotional modulation of startle responses is mediated by the amygdala (Davis, Walker, \& Lee, 1997), the key structure of the brain's fear network (LeDoux \& Phelps, 2000). Only phylogenetic FR stimuli were associated with enhanced startle responses, indicating that only these stimuli activated the amygdala fear network. Third, the close correspondence between $\mathrm{CB}$ (a cognitive measure) and modulation of the startle response (a purely physiological measure) validates the former and suggests a strong association between both measures. Fourth, although both groups exhibited disorder-specific SCR responses triggered by their feared FR stimuli, these responses habituated with different temporal characteristics (faster) in flight-phobic participants than in spider-phobic participants during the repeated presentation of their feared stimuli. In sum, it seems reasonable to conclude that startle response and SCR have in common that they are physiological fear responses, but they are controlled by different brain areas which are affected differently by situational information (see Hamm \& Vaitl, 1996).

ERP averages have to be based on a considerable number of artifact-free trials, and therefore an ERP analysis differentiating between experimental blocks was not possible. Enhanced positive ERPs were previously found after the presentation of arousing stimuli (Amrhein et al., 2004; Cuthbert et al., 2000) and were mainly interpreted as indicating a deep and attention-demanding processing of these stimuli involving more cortical resources (Cuthbert et al., 2000). However, ERP differences between ontoand phylogenetical FR stimuli were, to our knowledge, never examined. Enhanced P3 and PSW amplitudes for spider- and flight-phobic participants were found following the presentation of their feared FR stimuli compared to other stimuli. However, this effect was greatly stronger, longer lasting, and more widespread across electrodes for phylogenetic FR stimuli in spider-phobic participants than for ontogenetic FR stimuli in flight-phobic participants. Therefore, it might be concluded that phylogenetic fear is associated with a deeper and/or more biased processing of the corresponding FR stimuli. The cortical "fear network" responsible for the processing of FR stimuli might be more widespread and might have stronger interconnections for phylo- compared to ontogenetic fears.

Furthermore, flight- and spider-phobic participants differed in the spatial distribution of the ERP activity. Spider stimuli triggered in spider-phobic participants an enhanced ERP activity widely distributed across frontal and central brain areas, while airplane pictures elicited in flight-phobic participants enhanced ERP activity at one parietal location only. This topographical difference may indicate that the processing of phylogenetic relevant stimuli recruits widespread and/or deep neuronal networks, and especially the amygdala fear network with its strong associations to the frontal cortex may be involved. Unfortunately, ERP data do not allow clear topographic conclusions, and further research is needed to identify the involved neuronal sources.

Results were not as clear for earlier or later EKP components. First, the N2, a measure of selective attention (selection negativity; Harter, Aine, \& Schroeder, 1984), revealed no picture type effect for spider-phobic participants, but did for flight-phobic participants. Only flight-phobic participants showed enhanced N2 amplitudes triggered by their FR stimuli compared to other stimuli. However, this unexpected result requires replication to allow any profound interpretation. Second, the CNV can be differentiated into an initial $\mathrm{CNV}$, which presumably is stimulus driven and reflects further emotional processing, and a terminal $\mathrm{CNV}$, which should be more dependent on the motivational relevance and the emotional quality of an upcoming stimulus (Amrhein et al., 2005 Rockstroh, Elbert, Canavan, Lutzenberger, \& Birbaumer, 1989). Onto- and phylogenetic fear was associated with a more positive initial CNV triggered by the corresponding FR stimuli, a result that roughly corresponds to the present P3 and PSW results. However, the terminal CNV was not affected by any experimental manipulation; no difference between flight- and spider-phobic participants or between picture categories was found. This result is unexpected, since we reported terminal CNV effects in panic patients registered within an illusory correlation paradigm and interpreted them as an online measure of CB (Amrhein et al., 2005). Although the dif- 
ference between studies might reflect differences between panic patients and phobic patients, other differences between the examined populations or methodological differences due to fewer trials and other stimulus material have to be considered as well.

The age difference between our spider- and flight-phobic samples reflects these groups' age difference in the general population. Since this difference could affect results, analyses on physiological measures were conducted including age as covariate. There were no further group differences in other sociodemographic variables and psychopathology scales (e. g., SCL-90-R scales). In disorderspecific measures, flight-phobic participants scored about four standard deviations above the mean of the reference sample, while spider-phobic participants scored about three standard deviations above. Therefore, the weaker subjective and physiological responses of flight-phobic participants after the first and second experimental blocks cannot be explained by a moderate fear level, but presumably are a characteristic of ontogenetic fears.

The present study examined flight phobia as an example of ontogenetic fear, and airplane crashes were used as ontogenetic FR stimuli. Possible confounds might be that flight phobia incorporates several aspects of phylogenetic fear such as height, enclosure, and lack of escape possibilities, and by the same token that flight stimuli rendered a less accessible central phobic object compared to spider stimuli. However, we (Mühlberger, 2001) and others (van Gerwen, Spinhoven, \& Diekstra, 1997) have shown that the fear of an airplane crash is the most frequent and most prominent fear in flight-phobic participants. In addition, the observed initial expectancy bias, SCRs, and EKP reactions of flight-phobic participants indicated that airplane crashes were distinct fear triggers for these patients. Finally, the used flight stimuli did not depict features of height or enclosure. Therefore, we conclude that flight phobia predominately represents ontogenetic fear, and stimuli depicting airplane crashes can be considered ontogenetic FR stimuli.

In sum, our results confirm that both onto- and phylogenetic FR stimuli are associated with an expectancy bias and a heightened physiological reactivity triggered by FR stimuli (SCR, P3, and $\mathrm{CNV}$ ). However, the direct comparison between participants with ontogenetic or phylogenetic fear revealed that phylogenetic FR stimuli in contrast to ontogenetic FR stimuli trigger stronger CB and stronger physiological responses (ASR and PSW), reflecting a strongly biased processing of FR stimuli. Although repetitive situational information causes a correction of any observed processing bias, the registered response systems differed in the temporal characteristics of change due to situational information. In addition, this correction process caused by situational information was overall slower in spider-phobic participants compared to flight-phobic participants. These findings are in line with the preparedness hypothesis, suggesting a bias in the processing of phylogenetically relevant threat stimuli.

Further research should systematically replicate these results using other phylogenetic (e.g., snakes) or ontogenetic stimuli or other emotional responses (e.g., contamination-related disgust).

\section{References}

Alloy, L. B., \& Tabachnik, N. (1984). Assessment of covariation in humans and animals: The joint influence of prior expectations and current situational information. Psychological Review, 91, 112-149.

Amin, J. M., \& Lovibond, P. R. (1997). Dissociations between covariation bias and expectancy bias for fear-relevant stimuli. Cognition and Emotion, 11, 273-289.

Amrhein, C., Pauli, P., Dengler, W., \& Wiedemann, G. (2005). Covariation bias and its physiological correlates in panic disorder patients. Journal of Anxiety Disorders, 19, 177-191.

Amrhein, C., Pauli, P., Mühlberger, A., \& Wiedemann, G. (2004). Modulation of event-related brain potentials during affective picture processing: A complement to startle reflex and skin conductance response? International Journal of Psychophysiology, 54, 231-240.

Codispoti, M., Bradley, M. M., \& Lang, P. J. (2001). Affective reactions to briefly presented pictures. Psychophysiology, 38, 474-478.

Cook, E. W., Melamed, B. G., Cuthbert, B. N., McNeil, D. W., \& Lang, P. J. (1988). Emotional imagery and the differential diagnosis of anxiety. Journal of Consulting and Clinical Psychology, 56, 734-740.

Cuthbert, B., Schupp, H. T., Bradley, M. M., Birbaumer, N., \& Lang, P. J. (2000). Brain potentials in affective picture processing: Covariation with autonomic arousal and affective report. Biological Psychology, 52, 95111.

Davey, G. C. L. (1992). An expectancy model of laboratory preparedness effects. Journal of Experimental Psychology, 121, 24-40.

Davey, G. C. L., \& Dixon, A. L. (1996). The expectancy bias model of selective associations: The relationship of judgements of CS dangerousness, CS-UCS similarity and prior fear to a priori and a posteriori covariation assessments. Behaviour Research and Therapy, 34, 235252.

Davis, M., Walker, D. L., \& Lee, Y. (1997). Roles of the amygdala and bed nucleus of the stria terminalis in fear and anxiety measured with the acoustic startle reflex. Possible relevance to PTSD. Annals of the New York Academy of Sciences, 821, 305-331.

De Jong, P. J., \& Merckelbach, H. (1993). Covaration bias, classical conditioning, and phobic fear. Integrative Physiological and Behavioral Science, 28, 167-170.

De Jong, P. J., Merckelbach, H., \& Arntz, A. (1995). Covariation bias in phobic women: The relationship between a priori expectancy, on-line expectancy, autonomic responding, and a posteriori contingency judgment. Journal of Abnormal Psychology, 104, 55-62.

De Jong, P. J., Merckelbach, H., Arntz, A., \& Nijman, H. (1992). Covariation detection in treated and untreated spider-phobic participants. Journal of Abnormal Psychology, 101, 724-727.

Franke, G. H. (1995). SCL-90-R: Die Symptom-Check-Liste von Derogatis. Göttingen: Beltz Test Gesellschaft.

Gardner, W. L., Cacioppo, J. T., Crites, S. L., \& Berntson, G. G. (1994). A late positive brain potential indexes between subject differences in evaluative categorizations. Psychophysiology (Supplement 1), 31, S49S49.

Globisch, J., Hamm, A. O., Esteves, F., \& Öhman, A. (1999). Fear appears fast: Temporal course of startle reflex potentiation in animal fearful subjects. Psychophysiology, 36, 66-75.

Gratton, G. (1998). Dealing with artifacts: The EOG contamination of event-related brain potential. Behaviour Research Methods, Instruments, \& Computers, 30, 44-53.

Grillon, C., \& Ameli, R. (1998). Effects of threat of shock, shock electrode placement and darkness on startle. International Journal of Psychophysiology, 28, 223-231.

Grillon, C., Ameli, R., Goddard, A., Woods, S. W., \& Davis, M. (1994). Baseline and fear-potentiated startle in panic disorder patients. Biological Psychiatry, 35, 431-439.

Hamm, A. O., Cuthbert, B. N., Globisch, J., \& Vaitl, D. (1997). Fear and the startle reflex: Blink modulation and autonomic response patterns in animal and mutilation fearful subjects. Psychophysiology, 34, 97-107.

Hamm, A. O., \& Vaitl, D. (1996). Affective learning: Awareness and aversion. Psychophysiology, 33, 698-710.

Harter, M. R., Aine, C., \& Schroeder, C. (1984). Hemispheric differences 
in event-related potential measures of selective attention. Annals of the New York Academy of Sciences, 425, 210-211.

Haug, T., Brenne, L., Johnsen, B. H., Berntzen, D., Gotestam, K. G., \& Hugdahl, K. (1987). A three-systems analysis of fear of flying: A comparison of a consonant vs a non-consonant treatment method. Behaviour Research and Therapy, 25, 187-194.

Hugdahl, K., \& Kärker, A. C. (1981). Biological vs experiential factors in phobic conditioning. Behaviour Research and Therapy, 19, 109-115.

Johnsen, B. H., \& Hugdahl, K. (1990). Fear questionnaires for simple phobias: Psychometric evaluations for a Norwegian sample. Scandinavian Journal of Psychology, 31, 42-48.

Keil, A., Bradley, M. M., Hauk, O., Rockstroh, B., Elbert, T., \& Lang, P. J. (2002). Large-scale neural correlates of affective picture processing. Psychophysiology, 39, 641-649.

Kennedy, S. J., Rapee, R. M., \& Mazurski, J. (1997). Covariation bias for phylogenetic versus ontogenetic fear-relevant stimuli. Behaviour Research and Therapy, 35, 415-422.

Klorman, R., Weerts, T. C., Hastings, J. E., Melamed, B. G., \& Lang, P. L. (1974). Psychometric description of some specific-fear questionnaires. Behavior Therapy, 5, 401-409.

Kostandov, E. A., \& Arzumanov, Y. L. (1977). Averaged cortical evoked potentials to recognized and non-recognized verbal stimuli. ACTA Neurobiologiae Experimentalis, 37, 311-324.

Lang, P. J. (1980). Behaviour treatment and bio-behavioural assessment: Computer applications. In J. B. Sidowski, J. H. Johnson, \& T. A. Williams (Eds.), Technology in mental health care delivery systems (pp. 119-137). Norwood, NJ: Ablex.

Lang, P. J. (1995). The emotion probe. Studies of motivation and attention. American Psychologist, 50, 372-385.

Laux, L., Glanzmann, P., Schaffner, P., \& Spielberger, C. D. (1981). Das State-Trait Angstinventar [The state-trait anxiety inventory]. Weinheim: Beltz Test.

LeDoux, J. E., \& Phelps, E. A. (2000). Emotional networks in the brain. In M. Lewis \& J. M. Haviland-Jones (Eds.), Handbook of emotions (pp. 157-172). New York: Guilford Press.

McNally, R. J., \& Heatherton, T. F. (1993). Are covariation biases attributable to a priori expectancy biases? Behaviour Research and Therapy, $31,653-658$

Mühlberger, A. (2001). Exposition in virtuellen Welten zur Flugangsttherapie und experimentellen Therapieforschung [Exposure in virtual reality for the treatment of fear of flying and experimental therapy research]. Augsburg: Pinus Druck.

Naumann, E., Bartussek, D., Diedrich, O., \& Laufer, M. E. (1992). Assessing cognitive and affective information processing functions of the brain by means of the late positive complex of the event-related potential. Journal of Psychophysiology, 6, 285-298.

Öhman, A., \& Mineka, S. (2001). Fears, phobias, and preparedness:
Toward an evolved module of fear and fear learning. Psychological Review, 108, 483-522.

Pauli, P., Dengler, W., Wiedemann, G., Montoya, P., Flor, H., Birbaumer, N., et al. (1997). Behavioral and neurophysiological evidence for altered processing of anxiety-related words in panic disorder. Journal of $A b-$ normal Psychology, 106, 213-220.

Pauli, P., Diedrich, O., \& Müller, A. (2002). Covariation bias in the affect-modulated startle paradigm. Journal of Behavior Therapy and Experimental Psychiatry, 33, 191-202.

Pauli, P., Montoya, P., \& Martz, G.-E. (1996). Covariation bias in panicprone subjects. Journal of Abnormal Psychology, 105, 658-662.

Pauli, P., Montoya, P., \& Martz, G.-E. (2001). On-line and a posteriori covariation estimates in panic-prone individuals: Effects of a high contingency of shocks following fear-irrelevant stimuli. Cognitive Therapy and Research, 25, 103-116.

Pauli, P., Wiedemann, G., \& Montoya, P. (1998). Covariation bias in flight-phobic participants. Journal of Anxiety Disorders, 12, 555-565.

Rockstroh, B., Elbert, T., Canavan, A., Lutzenberger, W., \& Birbaumer, N. (1989). Slow cortical potentials and behaviour (2nd ed.). Munich: Urban \& Schwarzenberg.

Schupp, H. T., Cuthbert, B. N., Bradley, M. M., Birbaumer, N., \& Lang, P. J. (1997). Probe P3 and blinks: Two measures of affective startle modulation. Psychophysiology, 34, 1-6.

Schupp, H. T., Cuthbert, B. N., Bradley, M. M., Cacioppo, J. T., Ito, T., \& Lang, P. J. (2000). Affective picture processing: The late positive potential is modulated by motivational relevance. Psychophysiology, 37, $257-261$.

Seligman, M. E. P. (1971). Phobias and preparedness. Behaviour Research and Therapy, 2, 307-320.

Spielberger, C. D., Gorsuch, R. L., \& Lushene, R. E. (1970). State-Trait Anxiety Inventory. Palo Alto, CA: Consulting Psychologists Press.

Tomarken, A. J., Mineka, S., \& Cook, M. (1989). Fear-relevant selective associations and covariation bias. Journal of Abnormal Psychology, 98 , 381-394.

Tomarken, A. J., Sutton, S. K., \& Mineka, S. (1995). Fear-relevant illusory correlations: What types of associations promote judgmental bias? Journal of Abnormal Psychology, 104, 312-326.

van Gerwen, L. J., Spinhoven, P., \& Diekstra, R. F. W. (1997). People who seek help for fear of flying: Typology of flying phobics. Behavior Therapy, 28, 237-251.

vanOyen Witvliet, C., \& Vrana, S. R. (2000). Emotional imagery, the visual startle, and covariation bias: An affective matching account Biological Psychology, 52, 187-204.

Received November 10, 2004

Revision received July 5, 2005

Accepted July 28, 2005 